\title{
Revealing the Content of Industry 4.0: A Review of Literature
}

\author{
Alexander VESTIN ${ }^{\mathrm{a}, 1}$ Kristina SÄFSTEN ${ }^{\mathrm{a}}$ Malin LÖFVING ${ }^{\mathrm{ab}}$ \\ ${ }^{a}$ School of Engineering, Jönköping University P.O. Box 1026, 55111 Jönköping, \\ ${ }^{\mathrm{b}}$ Träcentrum Nässjö Kompetensutveckling AB, Box 174, 57122 Nässjö, Sweden
}

\begin{abstract}
A fourth industrial revolution is prophesied, and there is a potential for the industrialized world to proactively adapt suitable practices. Despite the large interest from both industry and academia, a drawback with the vast literature on initiatives that tap into the fourth industrial revolution, Industry 4.0 and alike, is the fuzziness when it comes to terminology and content. The terms are mixed up, and sometimes used interchangeable and the constituent parts are not fully described. The purpose of this paper is to present the content of initiatives related to the fourth industrial revolution in a structured manner. This is expected to support understanding for the content of the fourth industrial revolution and thereby facilitate the transformation. The results presented in this paper is based on a traditional literature review. In total 13 relevant review papers were identified. The identified papers were analyzed, and a framework was developed including technologies and design principles. In total, eleven technologies and twelve design principles were identified for Industry 4.0. The most frequently occurring technologies were Cyber physical systems, Internet of Things, and Big data. The most frequently occurring design principles were Smart factory, Service orientation and Sustainability and resource efficiency. A categorization of the content into technologies and design principles clarify and structures the content of Industry 4.0. The developed framework can support academics in identifying, describing, and selecting Industry 4.0 scenarios for further investigations. For practitioners, the framework can give a basic understanding and some guidance in their implementation journey of Industry 4.0.
\end{abstract}

Keywords. Industry 4.0, Smart manufacturing, Smart factory, Cyber physical systems, Internet of things

\section{Introduction}

The industrialized world is facing a fourth industrial revolution. For the first time, this revolution is prophesied, meaning that we can proactively apply and adjust suggested practices [1]. The fourth industrial revolution is expected to significantly change the technical, economic and social systems in industry [2]. The fourth industrial revolution is characterized by a high level of complexity and network integration of product and production processes [3]. Manufacturing industry has already begun its transformation, and as one example the German government launched the project Industrie 4.0 to tap into the fourth industrial revolution [4]. Industrie 4.0 is described as a new paradigm for

\footnotetext{
${ }^{1}$ Corresponding Author. Alexander.Vestin@ju.se
} 
improving productivity and flexibility through digitalization and is expected to deliver fundamental improvements to the industrial processes involved in manufacturing, engineering, material usage, supply chain and life cycle management [4]. Since 2011, when the project Industrie 4.0 was launched at the Hannover Fair, the fourth industrial revolution is sometimes referred to as Industry 4.0. Several similar initiatives have been launched, such as Smart Manufacturing in US and Smart Factory in Korea [5, 6]. The different initiatives have many similarities and are often used as synonyms to denote the fourth industrial revolution $[5,6]$. For this paper, we apply Industry 4.0 as a common term for various initiatives related to the fourth industrial revolution.

Despite (or maybe because of) the large interest from both industry and academia, a drawback with the vast literature on initiatives that tap into the fourth industrial revolution, Industry 4.0 and alike, is the fuzziness when it comes to terminology and content. The content of these initiatives has been described as for example technologies [3, 6-8], building blocks [9], design principles [7, 10, 11], components [11], tools [12] and similar terms. The terms are mixed up, and sometimes used interchangeable and furthermore, the constituent parts are not fully described. There is still no consensus on terminology and content of these initiatives [3].

Initiatives that intends to describe the fourth industrial revolution and the involved technological advancements are fuzzy. The fourth industrial revolution might be in a near future, organizations need to prepare themselves to embrace this potential, to remain competitive in the fierce and competitive market. Since the content of the initiatives themselves are unclear, organizations are struggling to identify and implement activities related to the understanding and transformation to the fourth industrial revolution $[7,10]$.

The purpose of this paper is to present the content of initiatives related to the fourth industrial revolution in a structured manner. This is expected to support understanding for the fourth industrial revolution and thereby facilitate the transformation. To achieve the purpose two research questions are formulated:

RQ1: What are the components of Industry 4.0?

RQ2: How can the components of Industry 4.0 be structured to support the transformation?

The rest of the paper follows a traditional structure. Initially we present the selected research methods and logic applied for the analysis. Thereafter the content of Industry 4.0 is revealed with a theoretical framework. Finally, the findings are discussed, and conclusions are drawn.

\section{Methodology}

This paper is based on a traditional literature review [13]. The literature review search was on Industry 4.0 with synonyms in the search engine Scopus. The search was limited to, document type; review, language; English and year from 2015 - 2019. The first search resulted in 154 papers. Next step was a screening of title and abstract for eligibility, that the papers where focused on several components of the initiative not just on a certain component. During this process snowballing techniques were also used on papers that seemed interesting [14]. In total 13 relevant papers were identified. These 13 papers went through a content analysis [15].

From the content analysis it could be established that Industry 4.0 is considered to be an unclear term $[7,10]$ and there is no consistent classification of components of the content of Industry 4.0. Source triangulation was used in the content analysis to ensure 
the validity of the components [16]. The component had to be represented in more than one paper to be included, twenty-three components were found. Some components resembled each other, and these were gathered into one component, e.g. cloud computing, cloud manufacturing and the cloud or e.g. service orientation and new business models etc.

It should be added that the original references were traced for the 23 components found in the 13 papers. This was also done to be able to elaborate further on the components.

All 23 components were structured based on a framework divided into two categories, technologies and design principles. The number of occurrences of the technologies and design principles in the 13 reviewed papers were also analyzed. This was done to give an indication of the most frequently occurring technologies and design principles. For the components that resembled each other, and gathered into one component, e.g. cloud computing, cloud manufacturing and the cloud, duplicated references were not counted. The technologies or design principles with the same number of occurrences were sorted based on alphabetic order.

\section{Revealing the content of Industry 4.0}

Several of the reviewed articles [1, 7, 9-11, 17] described the components of Industry 4.0 in terms of technologies and/or design principles. Based on this, a framework was developed based on these two components. Technologies describe the advanced digital technological innovations that, if used, can ascent the new digital industrial technology $[1,18]$. Design principles address the issue of fuzziness in Industry 4.0 by giving a systemization of knowledge and describing the components of this phenomenon [7, 10, 19]. The design principles allow manufacturers to anticipate the adaptation progress of Industry 4.0, and give them the "how to do" knowledge in developing suitable methods and solutions required for Industry 4.0 transition [7]. In this chapter the content of Industry 4.0 is described with the framework

\subsection{Technologies of Industry 4.0}

The technologies are sorted based on frequency of occurrence in the reviewed papers, see table 1 for an overview and source.

Cyber physical systems (CPS) [3, 5-11, 17, 20-22] is closely linked to Internet of things (IoT), described below. In addition to the IoT, CPS enables the fusion of the physical and the virtual world, through the integration of computing and physical processes [4]. CPS integrate imaging and control functionalities into the relevant systems. With this technology systems can respond to any feedback generated e.g. performance data of a machine. Which allow instant control and check of process feedbacks for the sake of generating needed outputs [11]. Lee et al. [23] suggested the 5C framework for realizing CPS; (1) smart connection level, (2) data-to-information conversion level, (3) cyber level, (4) cognition level, and 5) configuration level. In short, CPS consist of two important elements; A network of objects and systems communicating with each other over the internet with a designated address and, a virtual environment that is created by computer simulation of objects and behaviors in the real world [11]. CPS is also referred to as Cyber-physical production system (CPPS) [8, 9]. CPS/CPPS are often used interchangeably [8]. CPPS is an applied form of CPS in production [24]. 
Internet of things (IoT) [3, 5-11, 17, 20, 22] enables physical objects to communicate with each other and further to share information and to coordinate decisions [25]. IoT is the inter-networking of physical devices, vehicles, buildings, and other items embedded with electronics, software, sensors, actuators, and network connectivity that enable these objects to collect and exchange data [26]. IoT is also commonly referred to as Industrial Internet of Things (IIoT) [5, 12], which addresses the industrial application of IoT [27]. IIoT not only refers to the network of the physical objects in industry but also includes the digital representations of products, processes and manufacturing infrastructure such as 3D models or physical behavior models of machines [28].

Data is being generated continuously by everything in the surroundings. Every digital process and social media exchange produce data, transmitted by systems, sensors and mobile devices. Big data $[3,8,17,20,22]$ or big data analytics $[5-9,11,12,22]$ is a technology that can analyze large data sets including real-time data that are difficult to analyze with traditional methods [11]. Data analytics generally deals with turning the volume, variety, velocity and veracity of data into actions and insights within a manufacturing system [29]. Big data analytics can enable organizations to gain better value from the massive amounts of information they already have. Furthermore, it can identify what is likely to happen next and what actions should be taken to achieve the optimal results [30].

Cloud computing [3, 5, 7-9, 20, 22] provides manufacturers with cloud-based software application, web-based management dashboard and cloud-based collaboration [31]. This enables the integration of distributed manufacturing resources and establishment of a collaborative and flexible infrastructure across geographically distributed manufacturing and service sites [31]. Cloud manufacturing (CM) is also mentioned as a technology of Industry $4.0[6,8,9]$ and is driven by cloud computing [29]. $C M$ is a customer-centric manufacturing model that exploits on-demand access to a shared collection of diversified and distributed manufacturing resources. CM can form temporary and reconfigurable production lines that enhance efficiency, reduce product lifecycle costs, and allow for optimal resource loading in response to variable customer demand [32]. Some articles also use the term Cloud $[9,11,12]$. The cloud allows delivery of information much faster than standalone systems, quick updates, up to date performance models and other delivery options [11]. It is a mechanism for sharing information with collaborators. The cloud is characterized by its speed, which allows administrators to store data in the cloud and implement new systems to monitor and control processes through digital platforms [33].

With the use of internet, manufacturer strive to establish a direct link to consumers to strengthen their competitiveness [34]. This can be achieved with the technology Internet of Services (IoS) [3, 5-9, 11, 17, 21, 22]. Through sensor-based products information about product usage and condition is transferred to the manufacturer. This information can be used e.g. to charge the customer based on the usage of the product, or to deliver proactive and preventive maintenance of the product [35]. This technology pursuit a similar approach to IoT, however, it is applied to services instead of physical entities [17]. IoS can facilitate Product-as-a-service (PaaS) business model, which will be further described below in the design principle service orientation.

Augmented reality $(A R)[6-9,11,12,17,20,21]$ is an enhanced version of reality were live, direct or indirect, views of the physical real-world environments are enhanced with overlaid computer-generated images [11]. $A R$ is commonly used in real-time operation monitoring, fault diagnostic and recovery and training, related to industrial products and processes [36]. 
Automation and industrial robotics [5-9, 12, 17, 20, 21] promise numerous benefits such as reduced part cycle time, lower defect rate, higher quality and reliability, reduced waste and better floor space utilization [37]. Automation is about achieving a process or procedure performed with minimal human assistance, with support from software, machines and robots [38]. Robots can carry out difficult things and operate in dangerous and unfavorable conditions [11]. The demand for industrial robots has increased due to the ongoing trend toward automation among manufactures [7].

Simulation and modeling techniques [6-9, 12, 20, 21] aims for simplification and economic favoring of the design, realization, tests and running a live operation of manufacturing systems [39]. It evaluates the changes and behaviors in the configuration of machines, process flow and plant designs. It tests the effectiveness of the changes without them being realized, ensuring success under certain conditions, or rejecting the step of the operation [40]. Simulation and modeling enable manufacturers to prevent errors at an early stage that might otherwise result in substantial costs, it can also be used e.g. to optimize a manufacturing plant during ongoing daily operation [1].

Additive manufacturing or $3 D$ printing $[6-9,12,20]$ is a manufacturing technique in which parts are built by melting thin layers of powder and adding one layer of material, either plastic or metal, on top of another, based on the geometry of a Computer-Aided Design (CAD) modules [37]. Additive manufacturing enables manufacturers to produce prototypes and proof of concept designs, which simplify and speeds up the processes of new product design and manufacturing [1]. The technology also allows to obtain small samples without wasting material, which results in savings [41].

A sensor $[5,17,20,21]$ or sometimes referred as smart sensor $[6,8]$ is the most basic technology for collecting and controlling data in real-time [6]. This technology is one of the most important technologies at the device or hardware level in realizing IoT, $\mathrm{CM}$, and CPS [6].

Virtual reality (VR) $[6,8,9,20,21]$ creates a simulated environment that can be similar or completely different from the real world. It is possible to look around the artificial world, move around in it, and interact with virtual features or items [42]. VR is commonly used for educational purposes [42].

\subsection{Design principles of Industry 4.0}

The design principles are sorted based on frequency of occurrence in the reviewed papers, see table 1 for an overview and source.

Smart factory [3, 5-11, 17, 21, 22] is a key feature of Industry 4.0 when implementing IoT and CPS, this allows the creation of an intelligent environment along the entire value chain, enabling the performance of flexible and adaptive processes [4]. The environment in a Smart factory consists of an integrative real-time intercommunication between every manufacturing resource, sensors, machines, robots, humans, products etc. Implementing the Smart factory can increase the manufacturing efficiency and respond to highly complex market requirements [43]. Smart factory is also known as lights out factory, the most prominent feature is that they do not need human interference to work, hence the lights can be out [11]. In these factories, production is carried out entirely with robotic systems [11].

The emergence of new technologies in Industry 4.0 have changed the way products and services are sold and provided. Which affects traditional businesses models and brings new business opportunities [44] to the market. Such as Service orientation [3, 5$7,9,11,17,21,22]$, also referred to as New business models $[3,6,7,11,12,17,22]$. 
Manufacturing as a service (MaaS) and Product-as-a-service (PaaS) are new types of business models. MaaS rests at the foundation of the use of IoT and cloud computing and the interconnectivity between manufacturers. With these technologies it is possible for the companies to communicate their manufacturing needs and capacities automatically, this can shift the physical product as the primary goods to the production capacity of manufacturers, known as MaaS [45]. The PaaS business model rest at the foundation of IoS and Smart products to monitor when and how the products are used. Products are offered as a service or virtualized experience. Instead of a single direct payment, customers can subscribe to the product and pay e.g. a monthly fee[7].

When implementing Industry 4.0, Sustainability and resource-efficiency [5-9, 11, 20-22] should be in the focus of the design of industrial manufacturing processes. The realization of sustainability and resource efficiency enables efficient coordination of the product, material and energy all throughout the product life cycle [46]. This is a fundamental framework for a successful product [21].

Industry 4.0 is all about collecting real-time, and real-world data through a range of different dimensions, from factory, product, business partners etc. this Real-time capability [3, 6-11] is supported by IoT [23]. Although, it is not just about collecting data it is also to analyze in real-time and make decision in line with the results [47], as described in the technology big data analytics. Furthermore, the design principle virtualization described below is also heavily dependent on real-time data.

The design principle Decentralization [3, 7-10, 21] is the movement away from one large administrative center that disperse functions and powers across an organization. Decentralization enables different components in Industry 4.0 to work independently and make decisions autonomously, e.g. machines do not depend on human interference to work, even with exceptions, interferences and/or conflicting goals. The machine would still remain aligned with the path toward the single ultimate organizational goal $[1,8]$. Self-regulating systems and intelligent control mechanisms such as CPS enable decentralization. The embedded computers, sensors, and actors allows for monitoring and controlling the physical world autonomously, making automated decisions based on performance data $[10,21]$.

The design principle Interoperability $[3,6-9,11]$ is about the ability of two systems to exchange data, share information, to understand each other and to use functionality of one another [48]. To implement Industry 4.0 interoperability must be achieved between systems [49]. The architecture of interoperability can be divided in four levels: operational, systematical, technical, and semantic interoperability [3].

Modularity [3, 7-11] concerns the shift from linear manufacturing and planning, rigid systems and inflexible production models towards an agile system that can adapt to an ever-changing circumstances and requirements [1]. Modularity involves the entire production and manufacturing levels to the changing requirements of the market by replacing or expanding individual modules [8].

The working tasks will look different in Industry 4.0, employees will need to have other skills and the skills need to be developed to cope with new tasks [7, 50]. Industry 4.0 will demand for new skills and it is required by society and organizations to create opportunities for education of the required skills [51]. Hence, companies that aim for Industry 4.0 should focus on Skills development $[5-7,11,17,21]$ of their workforce [7, 50]. It is also expected that Industry 4.0 will create numerous job opportunities, especially related to informatics and mathematics and computer engineering [7]. The new required competency fields need to be included in curriculum designs in academic 
program [12]. To sum it up, more skilled staff will be required in technological fields to address Industry 4.0 requirements [51].

The design principle Virtualization [3, 7-11] can enable a replication of a digital twin of the entire value chain by merging sensor data acquired from the physical world into virtual or simulation-based models e.g. factory or product [40]. A virtual twin of a factory can enable testing different scenarios e.g. to optimize the functionality of production lines without disrupting the physical factory [1]. Virtualization is heavily dependent upon the real-time capability to be able to have and accurate digital twin [52].

Within Industry 4.0 environment, "things" are connected through the internet or amongst themselves to create a fully interconnected industrial networked environment across the supply chain. With the high number of interconnected things in Industry 4.0 it requires secure, safe and reliable communication to ensure that any decisions and actions are made based on dependable and properly authorized information [53]. The design principle Cybersecurity $[6-9,12]$ should incorporate security mechanisms that provide confidentiality, authenticity, integrity, access control etc. These mechanisms can be used to prevent computer and network intrusions and attacks. Furthermore, a cybersecurity architecture should have autonomic detection and response to cyberattacks with prevention techniques in order to achieve effective and robust cybersecurity systems [54].

Smart products $[3,7-9,17]$ is the new generation of physical products that can with different types of sensors embedded to them, communicate with the environment, collect, store and transfer data, during their life cycles [55]. Smart products are characterized by several key features such as computation, data storage, communication and interaction with their environment, being able to identify themselves, storing data about their production process and providing information about further steps regarding production and maintenance [55]. These type of product can facilitate Product-as-a-service (PaaS) business model [1], described above.

The design principle System integration [7, 12, 17, 22] refers to the process of bringing together the component subsystems into one system to ensure that the system is able to deliver the intended functionality [7]. There exist three different types of integration, End-To-End, Horizontal, and Vertical integration. End-To-End Engineering Integration refers to the integration of a continuous and consistent product model that can be used in every stage. In a product-centric value creation process, a chain of activities is performed e.g. customer requirement expression, product design and development, production engineering etc. The product model should be possible to use in every stage [22]. In the fields of production and automation engineering and IT, horizontal integration refers to the integration of the various IT systems used in the different stages of the manufacturing and business planning processes that involve an exchange of materials, energy and information both within a company (e.g. inbound logistics, production, outbound logistics, marketing) and between several different companies (value networks) [4]. Vertical integration refers to the integration of the various IT systems at the different hierarchical levels within a company (e.g. the actuator and sensor, control, production management, manufacturing and execution and corporate planning levels) [4].

\subsection{Summary of the technologies and design principles of Industry 4.0}

The content of Industry 4.0 revealed eleven technologies and twelve design principles. The technologies with the most occurrences in the 13 reviewed papers are; CPS, IoT and big data. The design principles with the most occurrences in the 13 reviewed papers are; 
Smart factory, Service orientation and sustainability and Resource efficiency, see table 1.

Table 1. The content of Industry 4.0 categorized into technologies and design principle, organized in the order of most occurrences in the reviewed articles.

\begin{tabular}{|c|c|c|c|}
\hline Technologies & $\begin{array}{c}\text { Number of occurrences } \\
\text { [source] }\end{array}$ & Design principles & $\begin{array}{c}\text { Number of occurrences } \\
\text { [source] }\end{array}$ \\
\hline Cyber physical systems & $12[3,5-11,17,20-22]$ & Smart factory & $11[3,5-11,17,21,22]$ \\
\hline Internet of things & $12[3,5-12,17,20,22]$ & Service orientation & $10[3,5-7,9,11,12,17,21,22]$ \\
\hline Big data & $11[3,5-9,11,12,17,20,22]$ & Sustainability and & $9[5-9,11,20-22]$ \\
\hline Cloud & $10[3,5-9,11,12,20,22]$ & resource efficiency & \\
\hline Internet of services & $10[3,5-9,11,17,21,22]$ & Real-time capability & $7[3,6-11]$ \\
\hline Augmented reality & $9[6-9,11,12,17,20,21]$ & Decentralization & $6[3,7-10,21]$ \\
\hline Automation and & $9[5-9,12,17,20,21]$ & Interoperability & $6[3,6-9,11]$ \\
\hline industrial robotics & & Modularity & $6[3,7-11]$ \\
\hline Simulation and modeling & $7[6-9,12,20,21]$ & Skills development & $6[5-7,11,17,21]$ \\
\hline Additive manufacturing & $6[6-9,12,20]$ & Virtualization & $6[3,7-11]$ \\
\hline Sensor & $6[5,6,8,17,20,21]$ & Cybersecurity & $5[6-9,12]$ \\
\hline \multirow[t]{2}{*}{ Virtual reality } & $5[6,8,9,20,21]$ & Smart product & $5[3,7-9,17]$ \\
\hline & & System integration & $4[7,12,17,22]$ \\
\hline
\end{tabular}

\section{Discussion and conclusion}

Industry 4.0, Smart manufacturing and initiatives alike, intends to highlight the fourth industrial revolution and is considered to be more fuzzy than concrete $[8,10,56]$. The purpose of this paper is to present the content of initiatives related to the fourth industrial revolution in a structured manner. This is expected to support understanding for the fourth industrial revolution and thereby facilitate the transformation. For this paper, we apply Industry 4.0 as a common term for various initiatives related to the fourth industrial revolution.

A framework was developed categorizing the content of Industry 4.0 into technologies and design principles, which was in line with several of the reviewed articles [1, 7, 9-11, 17]. A traditional literature review was conducted, and eleven technologies and twelve design principles were found.

The findings can be compared to Saucedo-Martínez et al. review [12] were Industry 4.0 was categorized into only 9 blocks, mixing technologies and so called "tools" together. This comparison also shows the fuzziness when it comes to terminology and categorization of components of Industry 4.0.

The findings of this paper can also be related to Ghobakhloo et al. [7] were a similar categorization framework was used. In Ghobakhloo et al. [7] twelve design principles and fourteen technology trends are listed. Although, in the twelve design principles, horizontal integration and vertical integration are listed as separated design principles. Compared to the findings of this paper were these components are considered to be a part of the design principle System integration. Furthermore, End-To-End Engineering Integration is not mentioned in Ghobakhloo et al. [7] although it is a highly referenced component of Industry 4.0 [4].

The fourteen technologies listed in Ghobakhloo et al. [7], consisted of 4 technologies only represented in that specific paper. Since source triangulation was used to strengthen the validity of this paper, these four technologies were excluded from the findings. These technologies were; Blockchain, Internet of people, Internet of data, and Semantic 
technologies. However, Ghobakhloo et al. [7] is one of the most recent published articles of the 13 papers analyzed. This could indicate that these technologies are new in the Industry 4.0 concept and that the concept keeps evolving. To conclude, the identification and compilation of eleven technologies and twelve design principles in this paper is comprehensive and representative for the literature.

The eleven technologies and twelve design principles identified in this paper were also analyzed based on number of occurrences. The most frequently occurring technologies were CPS, IoT and Big data. The most frequently occurring design principles were Smart factory, Service orientation and Sustainability and resource efficiency.

This can be compared to Saucedo et al. [12], where the technologies with most occurrences were, the IIoT, big data and additive manufacturing. Furthermore, according to $\mathrm{Lu}$ [3], the key technologies of Industry 4.0 are cloud computing, big data and IoT. Additionally in Pereira et al. [17] the key technologies for Industry 4.0 are declared as CPS, IoT and IoS. These are similar results compared to this study. This could indicate that these technologies should be especially considered when trying to adopt to the fourth industrial revolution.

None of the reviewed articles had structured design principles based on most occurrences. This might indicate that all design principles must be considered when implementing Industry 4.0. Although, according to Kang et al. [6], the most important design principle for the realization of Industry 4.0 is interoperability.

The contribution of this study is both academic and practical. The technologies and design principles identified in this paper help to clarify the content of Industry 4.0. The technologies and design principles can support academics in identifying, describing, and selecting Industry 4.0 scenarios for further investigations. The results from the study is also relevant among practitioners, since it is expected to support understanding of the components of Industry 4.0 and thereby facilitate the transformation.

Industry 4.0 will not only affect the economy and manufacturing industries, yet the whole society, education, health and law $[1,2]$. The findings of this paper indicate that a digital transition is required to implement Industry 4.0. This transition can seem overwhelming for companies with all the technologies and design principles identified. However, it is important to note that it is not necessary for companies to have every design principle and technology in place before embarking on a digitalization journey. Specific areas of companies operations can be digitalized first, for this, it is recommended to establish a transition strategy [7].

There is an uncertainty among manufacturers for how to approach implementation of Industry $4.0[7,10]$. More research is needed related to the possibility to implement design principles and technologies from Industry 4.0 in different industrial sectors. It would for example be beneficial to expand the framework and add effects on different systems level of specific technologies and design principles of Industry 4.0.

\section{Acknowledgement}

The authors of this paper would like to recognize the Knowledge Foundation for supporting the Industrial Graduate School ProWOOD+ which the corresponding author of this paper is a part of. 


\section{References}

[1] Gilchrist, A., Industry 4.0: the industrial internet of things, Apress, Berkeley, CA, 2016.

[2] Dombrowski, U. and T. Wagner, Mental strain as field of action in the 4th industrial revolution, Procedia CIRP, vol. 17, 2014, pp. 100-105.

[3] Lu, Y., Industry 4.0: A survey on technologies, applications and open research issues, Journal of Industrial Information Integration, vol. 6, 2017, pp. 1-10.

[4] Kagermann, H., J. Helbig, A. Hellinger, and W. Wahlster, Recommendations for Implementing the Strategic Initiative INDUSTRIE 4.0: Securing the Future of German Manufacturing Industry ; Final Report of the Industrie 4.0 Working Group, Forschungsunion, 2013.

[5] Thoben, K.-D., S. Wiesner, and T. Wuest, "Industrie 4.0" and smart manufacturing-a review of research issues and application examples, International Journal of Automation Technology, vol. 11, 2017, pp. 4-16.

[6] Kang, H.S., J.Y. Lee, S. Choi, H. Kim, J.H. Park, J.Y. Son, B.H. Kim, and S. Do Noh, Smart manufacturing: Past research, present findings, and future directions, International Journal of Precision Engineering and Manufacturing-Green Technology, vol. 3, 2016, pp. 111-128.

[7] Ghobakhloo, M., The future of manufacturing industry: A strategic roadmap toward Industry 4.0, Journal of Manufacturing Technology Management, vol. 29, 2018, pp. 910-936.

[8] Mittal, S., M.A. Khan, D. Romero, and T. Wuest, Smart manufacturing: characteristics, technologies and enabling factors, Proceedings of the Institution of Mechanical Engineers, Part B: Journal of Engineering Manufacture, vol. 2017, pp. 1342-1361.

[9] Mittal, S., M. Khan, D. Romero, and T. Wuest, Building Blocks for Adopting Smart Manufacturing, Procedia Manufacturing, vol. 34, 2019, pp. 978-985.

[10] Hermann, M et al., Design principles for industrie 4.0 scenarios, In: 49th Hawaii international conference on system sciences (HICSS), Kauai, 2016, pp. 3928-3937.

[11] Oztemel, E. and S. Gursev, Literature review of Industry 4.0 and related technologies, Journal of Intelligent Manufacturing, vol. 31, 2018, pp. 127-182.

[12] Saucedo-Martínez, J.A., M. Pérez-Lara, J.A. Marmolejo-Saucedo, T.E. Salais-Fierro, and P. Vasant, Industry 4.0 framework for management and operations: a review, Journal of Ambient Intelligence and Humanized Computing, vol. 9, 2018, pp. 789-801.

[13] Jesson, J., L. Matheson, and F.M. Lacey, Doing your literature review: Traditional and systematic techniques, Sage, London, 2011.

[14] Wohlin, C., Guidelines for snowballing in systematic literature studies and a replication in software engineering, In: Proceedings of the 18th international conference on evaluation and assessment in software engineering, New York, 2014, pp. 1-10.

[15] Seuring, S., Conducting content - analysis based literature reviews in supply chain management, Supply Chain Management: An International Journal, vol. 17, 2012, pp. 544-555.

[16] Säfsten, K. and M. Gustavsson, Research Methododolgy for engineers and other problem solvers, Studentlitteratur, Lund, 2020.

[17] Pereira, A. and F. Romero, A review of the meanings and the implications of the Industry 4.0 concept, Procedia Manufacturing, vol. 13, 2017, pp. 1206-1214.

[18] Liao, Y., F. Deschamps, E.d.F.R. Loures, and L.F.P. Ramos, Past, present and future of Industry 4.0 - a systematic literature review and research agenda proposal, International Journal of Production Research, vol. 55, 2017, pp. 3609-3629.

[19] Gregor, S., A theory of theories in information systems, In Gregor, S et al. (eds.): Information Systems Foundations: Building the Theoretical Base, Australian National University, Canberra, 2002 , pp. 1-20.

[20] Kusiak, A., Smart manufacturing, International Journal of Production Research, vol. 56, 2018, pp. 508-517.

[21] Lasi, H., P. Fettke, H.-G. Kemper, T. Feld, and M. Hoffmann, Industry 4.0, Business \& Information Systems Engineering, vol. 6, 2014, pp. 239-242.

[22] Wang, S., J. Wan, D. Li, and C. Zhang, Implementing smart factory of industrie 4.0: an outlook, International Journal of Distributed Sensor Networks, vol. 12, 2016, pp. 3159805.

[23] Lee, J., B. Bagheri, and H.-A. Kao, A cyber-physical systems architecture for industry 4.0-based manufacturing systems, Manufacturing letters, vol. 3, 2015, pp. 18-23.

[24] Monostori, L., Cyber-physical production systems: Roots, expectations and R\&D challenges, Procedia CIRP, vol. 17, 2014, pp. 9-13.

[25] Al-Fuqaha, A., M. Guizani, M. Mohammadi, M. Aledhari, and M. Ayyash, Internet of things: A survey on enabling technologies, protocols, and applications, IEEE communications surveys \& tutorials, vol. 17, 2015, pp. 2347-2376. 
Leloglu, E., A review of security concerns in Internet of Things, Journal of Computer and Communications, vol. 5, 2016, pp. 121-136.

[27] Wang, S., J. Wan, D. Zhang, D. Li, and C. Zhang, Towards smart factory for industry 4.0: a selforganized multi-agent system with big data based feedback and coordination, Computer Networks, vol. 101, 2016, pp. 158-168.

[28] Jeschke, S and C. Brecher, Industrial Internet of Things and Cyber Manufacturing Systems, In: Jeschke S et al. (eds.): Industrial Internet of Things: Cybermanufacturing Systems, Springer International Publishing, Springer, Cham, 2017, pp. 3-19.

[29] Yu, C., X. Xu, and Y. Lu, Computer-integrated manufacturing, cyber-physical systems and cloud manufacturing-concepts and relationships, Manufacturing letters, vol. 6, 2015, pp. 5-9.

[30] LaValle, S., E. Lesser, R. Shockley, M.S. Hopkins, and N. Kruschwitz, Big data, analytics and the path from insights to value, MIT sloan management review, vol. 52, 2011, pp. 21-32.

[31] He, W. and L. Xu, A state-of-the-art survey of cloud manufacturing, International Journal of Computer Integrated Manufacturing, vol. 28, 2015, pp. 239-250.

[32] Wu, D et al., Cloud manufacturing: drivers, current status, and future trends, In: ASME 2013 International Manufacturing Science and Engineering Conference, New York, 2013, pp.1-10.

[33] Juan-Verdejo, A and B. Surajbali, XaaS Multi-Cloud Marketplace Architecture Enacting the Industry 4.0 Concepts, In: Camarinha-Matos, Luis M. et al. (eds.): Technological Innovation for Cyber-Physical Systems, Springer International Publishing, Springer, Cham, 2016, pp. 11-23. Becker, T. and C. Burghart, Core Technologies for the Internet of Services, In Wahlster W et al. (eds.): Towards the Internet of Services: The THESEUS Research Program, Springer International Publishing, Springer, Cham, 2014, pp. 59-88.

Leminen, S and M. Westerlund, Towards IOT Ecosystems and Business Models, In Andreev, S et al. (eds.): Internet of Things, Smart Spaces, and Next Generation Networking, Springer Berlin, Heidelberg, 2012, pp. 15-26.

[36] Doshi, A., R.T. Smith, B.H. Thomas, and C. Bouras, Use of projector based augmented reality to improve manual spot-welding precision and accuracy for automotive manufacturing, The International Journal of Advanced Manufacturing Technology, vol. 89, 2017, pp. 1279-1293.

Esmaeilian, B., S. Behdad, and B. Wang, The evolution and future of manufacturing: A review, Journal of manufacturing systems, vol. 39, 2016, pp. 79-100.

Kolberg, D. and D. Zühlke, Lean automation enabled by industry 4.0 technologies, IFACPapersOnLine, vol. 48, 2015, pp. 1870-1875.

Kocian, J and M. Tutsch, Application of Modeling and Simulation Techniques for Technology Units in Industrial Control In Sambath, $\mathrm{S}$ et al. (eds.): Frontiers in Computer Education, Springer Berlin, Heidelberg, 2012, pp. 491-499.

Moreno, A., G. Velez, A. Ardanza, I. Barandiaran, Á.R. de Infante, and R. Chopitea, Virtualisation process of a sheet metal punching machine within the Industry 4.0 vision, International Journal on Interactive Design and Manufacturing, vol. 11, 2017, pp. 365-373.

Bogers, M., R. Hadar, and A. Bilberg, Additive manufacturing for consumer-centric business models: Implications for supply chains in consumer goods manufacturing, Technological Forecasting and Social Change, vol. 102, 2016, pp. 225-239.

Earnshaw, R.A., Virtual reality systems, Academic press, San Diego, CA, 2014.

Radziwon, A., A. Bilberg, M. Bogers, and E.S. Madsen, The smart factory: exploring adaptive and

flexible manufacturing solutions, Procedia Engineering, vol. 69, 2014, pp. 1184-1190.
Glova, J., T. Sabol, and V. Vajda, Business models for the internet of things environment, Procedia Economics and Finance, vol. 15, 2014, pp. 1122-1129.

Tao, F. and Q. Qi, New IT driven service-oriented smart manufacturing: framework and characteristics, IEEE Transactions on Systems, Man, and Cybernetics: Systems, vol. 49, 2017, pp. 81-91.

Stock, T. and G. Seliger, Opportunities of sustainable manufacturing in industry 4.0, Procedia CIRP, vol. 40, 2016, pp. 536-541.

Moeuf, A., R. Pellerin, S. Lamouri, S. Tamayo-Giraldo, and R. Barbaray, The industrial management of SMEs in the era of Industry 4.0, International Journal of Production Research, vol. 56, 2018, pp. 1118-1136.

Chen, D., G. Doumeingts, and F. Vernadat, Architectures for enterprise integration and

interoperability: Past, present and future, Computers in industry, vol. 59, 2008, pp. 647-659.
Liao, Y., L.F.P. Ramos, M. Saturno, F. Deschamps, E.d.F.R. Loures, and A.L. Szejka, The role of interoperability in the fourth industrial revolution era, IFAC-PapersOnLine, vol. 50, 2017, pp. 12434-12439.

[50] Pinzone, M and P. Fantini, Jobs and Skills in Industry 4.0: An Exploratory Research, In Lödding, $\mathrm{H}$ et al. (eds.): Advances in Production Management Systems. The Path to Intelligent, Collaborative 
and Sustainable Manufacturing, Springer International Publishing, Springer Cham, 2017, pp. 282288.

[51] Erol, S., A. Jäger, P. Hold, K. Ott, and W. Sihn, Tangible Industry 4.0: a scenario-based approach to learning for the future of production, Procedia CIRP, vol. 54, 2016, pp. 13-18.

[52] Schleich, B., N. Anwer, L. Mathieu, and S. Wartzack, Shaping the digital twin for design and production engineering, CIRP Annals, vol. 66, 2017, pp. 141-144.

[53] Mehnen, J and H. He, Practical Security Aspects of the Internet of Things In Thames, L et al. (eds.): Cybersecurity for Industry 4.0: Analysis for Design and Manufacturing, Springer International Publishing, Springer Cham, 2017, pp. 225-242.

[54] Thames, L. and D. Schaefer, Cybersecurity for Industry 4.0 and Advanced Manufacturing Environments with Ensemble Intelligence, In Thames, L et al. (eds.): Cybersecurity for Industry 4.0: Analysis for Design and Manufacturing, Springer International Publishing, Springer Cham, 2017, pp. 243-265.

[55] Schmidt, R and M. Möhring, Industry 4.0 - Potentials for Creating Smart Products: Empirical Research Results, In Abramowicz, W (eds.): Business Information Systems, Springer International Publishing, Springer Cham, 2015, pp. 16-27.

[56] Hofmann, E. and M. Rüsch, Industry 4.0 and the current status as well as future prospects on logistics, Computers in Industry, vol. 89, 2017, pp. 23-34. 